\title{
Linguistic and social factors in Turkish-Dutch contact across generations
}

\author{
Yeşim Sevinç* \\ University of Oslo
}

There are certain differences between Turkish as spoken in the Netherlands (NL-Turkish) and Turkish as spoken in Turkey (TR-Turkish). These differences concern issues of linguistic variation and change in immigrant communities and seem to be closely related to social, emotional and linguistic aspects of contact situations. Considering the fact that in a contact situation the social and linguistic relationships are crucial for the outcome of language change, this paper first examines the social values that three different generations give to the language and culture of their host and home communities; then, it discusses the linguistic consequences on the lexical and structural levels of NL-Turkish. The principal conclusion is that possible language shift in the third generation leads to intensive contact with Dutch language and culture, provokes the linguistic factors and, therefore, causes the lexical and structural changes in NL-Turkish.

Keywords: bilingualism, language contact and change, Turkish-Dutch, codeswitching, loan translation, language shift, (heritage) language anxiety.

\section{Introduction}

The cumulative effect of long-term accommodation by a whole community which settles in a host country can, after one generation or more, result in variation and change in social practices as well as in heritage language (Kerswill, 1994). The Turkish community in the Netherlands currently has three generations. Previous research on Turkish-Dutch language contact has documented the linguistic repertoire of this community but, so far, none of it has addressed the linguistic and social changes underfoot specifically in the third generation currently growing up.

\footnotetext{
* This work was partly sponsored by the Research Council of Norway through its Centres of Excellence Funding scheme, project number 223265
} 
When I go to Turkey on holidays, I try to play with my cousin's friends there, and I attempt to say something but I stop... They sometimes don't understand what I say and it gets worse... When I can't explain it in Turkish, I call my mother or father and tell them in Dutch. Then, they talk to them on the phone. That happens in Turkey often. (Sevinç, 2012, 5)

The situation above, experienced by a third generation Dutch-Turkish bilingual, indicates that, for the first time, there are signs of shift, with linguistic as well as emotional implications. When Turkish immigrants, particularly their second and third generation descendants, go to Turkey for a visit and find themselves in a monolingual environment where they are confronted with Standard Turkish, they become aware that there are certain differences between how they speak and how they should speak if they want to speak 'proper' Turkish. These differences concern issues of linguistic variation and change in immigrant communities and seem to be closely related to both social and linguistic aspects of contact situations.

With respect to the methodological aspects, many studies have examined the differences between NL-Turkish and TR-Turkish based on conversational data (Backus, 1996; Doğruöz, 2007). Sociolinguistic work on maintenance and shift made use of questionnaires (Yağmur, 2009). It is only recently that studies have started to explore other data sources that can provide new perspectives, including judgment tasks and controlled experiments (e.g. Doğruöz \& Gries, 2012; Onar Valk \& Backus, 2013). Contributing to this development, in the present paper, I summarize the results of my MA thesis research, which is relatively small-scale and can be considered a pilot study for related studies in the future. This pilot study investigates the Turkish language of three generations of Turkish immigrants in an experiment that elicited free response data in a controlled video description task, and in an interview related to the possible social factors involved in language change. It examines the social values that these different generations give to the language and culture of their host and home communities, and discusses the linguistic consequences on the lexical and structural levels of NL-Turkish. In somewhat more concrete terms, it links the impact of language maintenance and shift to the lexical and structural variations observed in NL-Turkish. It further demonstrates possible linguistic and social factors playing a role in these variations across generations.

The paper is structured as follows: this section presents social and linguistic perspectives and definitions of some general terms related to the Turkish-Dutch contact phenomena. The following section elaborates on the research methodology. Section 3 presents the findings, and the final section discusses these findings and offers suggestions for further study. 


\subsection{Social perspectives and assumptions}

Dutch-Turkish language contact has a history of around 50 years that started with labor immigration in the 1960s. At the present time, there are three generations of Turkish descent in the Netherlands. The first generation came to the Netherlands to work for a limited period of time and brought their families to the Netherlands afterwards or married someone from Turkey. Thus, in both cases spouses would be mostly monolingual. These families mainly consist of Turkey-born spouses who have close ties within the community, visit Turkey, watch Turkish TV channels frequently, and, indeed, give high value to speaking Turkish and the maintenance of Turkish (Backus, 2013; Yağmur, 2009).

The term 'second generation' in this study is simply used for people who were born in the Netherlands or arrived there at a very early age, but in any case went to school in the Netherlands. The level of Dutch of the second generation is higher than that of the first generation as they have been exposed more to the Dutch language. On the other hand, most of them married someone originally from Turkey. However, with one bilingual parent, it is likely that the Turkish dominance at home decreases in the daily life of the next generation. Currently, with the oldest of these children at an age of 17, the third generation is taking shape. For the first time, we see a generation that is born and raised in the Netherlands and is more exposed to Dutch than to Turkish.

Different components of language maintenance and shift (e.g. language proficiency, language choice, attitude toward languages and cultures) have been investigated in first and second generation of the Turkish community in the Netherlands through questionnaires on language skills and language use and choice patterns (cf. Phalet \& Güngör; 2004; Vedder \& Virta, 2005; Extra \& Yağmur, 2010). Although quantitative research is important, in order to delve deeper into social and psychological aspects of the immigrant experience, we need more than numbers. Talking with members of the community and listening to them can reveal some crucial insights about their sense of belonging and identity, and social interactions as well as their emotions. As described in Yağmur $(2009,219)$, "birth country turns out to be a significant factor for Dutch language skills of Turkish immigrants". In this paper, based on the results of interviews with 14 bilinguals across three generations, I hypothesize that country of birth might also cause other significant differences across generations with respect to social-emotional as well as linguistic aspects in Turkish-Dutch contact. Comparing informants' emotions while talking both Turkish and Dutch, I furthermore present some assumptions on bilinguals' language anxiety - a topic which in the context of bilingualism has only been brought up in relation to foreign language learning (cf. MacIntyre \& Gardner, 1991; Dewaele, Petrides, \& Furnham, 2008). 


\subsection{Linguistic perspectives and assumptions}

A change in a language starts only when an unconventional construction starts to be used by other members of the speech community (Croft, 2000). The term 'unconventional' refers to the elements in a language that violate a rule or convention and sound odd to native speakers of that language. Unconventionality and change in NL-Turkish have been examined mostly based on conversational data (e.g. Backus, 1996; Doğruöz, 2007) and only recently by means of other data sources, including judgment tasks and controlled experiments (e.g. Doğruöz \& Gries, 2012; Onar Valk \& Backus, 2013). A main agreement among these studies is that slowly but surely new varieties of Turkish seem to emerge in the NL-Turkish structure and lexicon due to contact with Dutch. However, the question of whether these new varieties occur in the speech of other members across three different generations is still up in the air.

Discussing variation and unconventionality in NL-Turkish first requires a look at the possible factors that determine the outcomes of Turkish-Dutch contact.

Structural variation and change are much influenced by the degree of 'typological distance' between the source and receiving languages (Field, 2002). Differences between Dutch and Turkish structure and syntax make some constructions more vulnerable to change. For instance, Turkish has six cases: nominative, which does not have a suffix, and five others: accusative, dative, genitive, locative, and ablative, each marked with its own suffix. Since Dutch does not have an equally elaborate case system, confusion in the use of case markers may occur in the bilinguals' speech. Another factor is that 'intense contact' (Thomason \& Kaufman, 1988) is more likely to affect typological restructuring of the receiving language (here NL-Turkish). It refers to the situations when speakers of the receiving language (Turkish) adopt features from the source language (Dutch), or to imperfect learning, where native speakers of the source language have learned the receiving language imperfectly (e.g. due to lack of exposure to Turkish in Turkey). In the current study, intensity of contact is addressed through interview data. It is expected that younger generations have been exposed more to Dutch than Turkish. As a possible effect, direct influence of Dutch on Turkish - 'interference' - could be expected (see Backus, 2010; Grosjean, 2012).

Intensity of contact also affects the lexicon. According to Thomason and Kaufman (1988), 'borrowability' relates the intensity of contact to the items that are borrowed. When the intensity is at the minimum level, only lexical content words are borrowed and as the intensity increases, function words and some simple structures may follow, and with intensive contact, almost anything can be borrowed. Additionally, 'attractiveness', as presented by Johanson (2002), is an alternative way of looking at what determines borrowability. It suggests that some 
words are more attractive than others, which means they are either more easily borrowed from Dutch or, alternatively, more resistant to replacement by a Dutch equivalent.

Finally, some terms related to possible phenomena in NL-Turkish need to be clarified. Inclusion of one or more content words from Dutch into Turkish is taken as 'insertional code-switching' (Muysken, 2000). If a content word becomes entrenched as a conventional word and starts to be used by other informants too, it is counted as an 'established loan word' (see Backus \& Dorleijn, 2009). In this context, Grosjean (2012) suggests that the only way to distinguish code-switching from borrowing (loanword usage) is to put bilingual speakers in a strict monolingual mode. Methodologically, this paper adopts this approach. The term 'loan translation' refers to any unconventional usage of a word, collocation or idiom in Turkish as a result of the word for word translation of a semantically equivalent expression in Dutch. The use of the Turkish infinitive yapmak ('do'/'make') with Dutch words, finally, was extensively discussed in Backus (2009), where he also states that all Dutch verbs are inserted as in (1), in their infinitive form and followed by an inflected form of yapmak:

(1) Biz bugün uitgaan yap-1yor-uz.

we today go.out.INF do-PROG-1PL.

'We're going out today'. (Backus, 2009, 320)

The linguistic phenomena and assumptions discussed here are further elaborated with examples from the current data in Section 3.2.

\section{Method}

The data in this study was collected via a controlled elicitation task and an interview with 14 NL-Turkish speakers (7 first, 3 second and 4 third generation) aged 12-60 years. All first and second generation informants had completed higher education, except for two who were still at university (Ozlem and Mesut). All third generation informants were still in college, and had parents with a university degree.

All participants were tested individually in a quiet room by myself - a native Turkish speaker with only a basic level of Dutch. Before, during and after the experiments, I spoke only Turkish. Thus, the main language of interaction between the participants and the researcher was Turkish. In addition, following Grosjean (2012), the participants were asked to retell the videos in Turkish monolingual mode, so they would switch to Dutch only when they felt unable to find the equivalent of a specific word or phrase in Turkish. This helped me to find Dutch 
vocabulary and structure that is likely to be entrenched in NL-Turkish. The informants first performed the controlled elicitation task and then the interview. Each experimental session took 40-65 minutes.

The controlled elicitation task consisted of 83 video clips. Sixty-nine videos were 10 seconds long; the subjects had to describe these after watching them. The other 14 videos were between 10 and 180 seconds long; these had to be described while playing. Eight of the clips were commercial movie clips and the rest were recorded specifically to elicit linguistic responses. Some of them were animated and some of them had actors. Portraying daily activities (washing something, eating, preparing a meal, etc.) as well as more complicated problem solving events (being unable to sleep due to noise and solving this), the video clips made the informants produce specific structures with a varied vocabulary for encoding materials, actions, statements, emotions, and spatial relationships.

The interview questions were related to the informants' demographic information, their age of arrival, language background, value and importance of Turkish and Dutch, feelings about these languages and their identities, social interaction and language choice. They were asked about the languages spoken at home, at school, and at work and the amount of Turkish in their life, e.g. the frequency of watching Turkish TV channels, reading books/newspaper, using computer and internet in Turkish, talking with friends and relatives, and visiting Turkey.

To analyze lexical and structural variation and changes in the participants' use of Turkish, total number of words, Dutch items and unconventional Turkish items were identified for each individual. Unconventional utterances ${ }^{1}$ were listed according to their source: lexical, structural, Dutch meaning and combinations (loan translations) and Dutch overt word and combinations (Dutch words followed by Turkish infinitive yap-('to do')). Among these, the most commonly used words or phrases across three generations were ranked by frequency. Finally, considering the two aspects - frequency and being used by different people - the overt Dutch words, unconventional phrases and forms were classified as becoming entrenched in NL-Turkish or not. The interviews were evaluated to verify the possible relation between the sociolinguistic background of the bilinguals, language maintenance and shift, and the results of the elicitations. Tentative interpretations are offered about the relation between the participants' performance in Turkish and their sociolinguistic profiles.

1. Recall that the term 'unconventional' refers to the elements in NL-Turkish that violate a rule or convention in TR-Turkish and sound odd to TR-Turkish speakers. To be sure if these elements are 'unconventional', I double checked them with other native speakers in Turkey. 


\section{Findings}

In this section, I will first provide the results of the interviews, followed by those of the elicitation experiment.

\subsection{Findings based on interviews}

Informants' responses on interview questions take us through three components of language maintenance and shift: language proficiency, use and preference, and feelings and attitudes toward two languages and cultures. Some important points will be illustrated with the notes from the interviews, while overall amount of daily Turkish use will be summarized by means of percentages.

\section{Language proficiency, use and preference}

Based on the self-evaluations - which were provided in the form of percentages, Table 1 presents the degree of daily use of Turkish.

Table 1. Percentages of immigrants' use of Turkish in their daily life

\begin{tabular}{llcc}
\hline Generation & Participants & Turkish usage & Mean \\
\hline 1 & Nejat & 90 & \\
& Sulhiye & 100 & \\
& Mine & 90 & \\
& Gunay & 40 & \\
Demet & 20 & \\
& Gulsum & 50 & 61 \\
& Yunus & 40 & \\
& Nilay & 60 & 40 \\
& Ozlem & 10 & \\
& Mesut & 50 & \\
& Tolga & 20 & \\
& Sare & 20 & 18 \\
\hline
\end{tabular}

The percentages vary particularly among the speakers from the first generation. Gulsum, Yunus, and Gunay, who all work for a Dutch company, indicated that they have to speak Dutch at work. Demet uses Turkish the least (20\%) and speaks Dutch more often, because her husband is a native speaker of Dutch and he does 
not speak Turkish. Without any exceptions, all of the first generation immigrants indicated that they are more fluent in Turkish since it is their 'native' language their 'own' language. They watch Turkish channels very often, read Turkish books and newspapers, and they talk only Turkish as much as they can. They have more Turkish than Dutch friends, and they are often in contact with other Turkish families in the Netherlands and with their own relatives in Turkey.

There is also much variation between the speakers of the second generation. Nilay, who works for a Turkish social organization, indicated that at work she needs to speak Turkish more than Dutch, and Mesut, who is a university student, speaks Turkish with his parents and Dutch with his Dutch friends at school. On the other hand, Ozlem, who has a Dutch boyfriend and spends most of her time with him, rarely speaks Turkish. All three informants noted that they can express themselves much better in Dutch than in Turkish.

As for the third generation, when I asked for the reason why they use Turkish less than Dutch, they all indicated that they spend most of their time with their Dutch friends at school and outside, and at home they prefer to speak Dutch since their Turkish is not so good.

Despite the variation, the average percentage of Turkish use in the first generation $(61 \%)$ is higher than that of the second (40\%) and third generations (18\%). Six out of 7 informants from the second and third generations mentioned that being born and growing up in the Netherlands plays a big role in their low proficiency in Turkish. This brings to mind the abovementioned factors 'intensity contact with Dutch' and 'lack of exposure to Turkish'.

\section{Feelings and attitudes toward Turkish and Dutch}

Interviews also revealed differences in feelings and attitudes across the three generations. The following questions were asked: 'Can you tell me about the importance of the languages to you?', 'Can you tell me about your feelings when you visit Turkey, when you talk languages', 'What's the practical and emotional value of Dutch/Turkish?' and 'How do you feel about your identity?'.

In general, first generation immigrants emphasized the importance of Turkish as 'their native language' or 'their own language', while they consider Dutch merely a tool to make life in the Netherlands easier. They principally support the use of Turkish consistently and are adamant about their children retaining their native culture, looking for ways and means to maintain fluency in their mother tongue. A quote from Yunus expresses his strong emotional bond with Turkish:

Türkçe'nin değeri paha biçilmez. Hollandaca bende sadece bir araç. Ben aslinda Hollandaca'yı daha çok bir katil, bir suçlu olarak görüyorum, kendi dilimi unutmama sebep olduğu için. 
'The value of Turkish is priceless. To me Dutch is only a tool. In fact, I consider Dutch more as a murderer, as a criminal, since it makes me forget my own language.'

The emphasis on 'my own language' and 'my own culture' was not found in the interviews of the second and third generations. The second generation seemed to steer a neutral course: on the one hand they try to keep what was instilled in the family and on the other hand they will stimulate their children to quickly assimilate into Dutch society by learning Dutch as soon as possible. They all remarked that they may get married to a Dutch person, and even though they will teach their kids Turkish in the future, they believe that Dutch will be the primary language. All of them agreed that they feel closer to Dutch language and culture, since they were born in the Netherlands. Unlike the first generation, they highlighted the emotional and practical value of Dutch in their life in addition to the important position of Turkish.

Meanwhile, it seemed the third generation shows the least maintenance of Turkish and the most extensive adjustment to the Netherlands. None of them think they need Turkish. They emphasized that Dutch is their own language and they feel more like a Dutch person. Additionally, negative opinions regarding Turkish culture and TV channels were noted during the interviews:

Türk kanalları sevmiyorum saçma sıkıcı geliyor. Daha çok Hollandaca programlar izliyorum, ingilizce altyazll oluyor ve Hollandaca kitap okuyorum.

'I don't like Turkish channels, I find them rubbish and boring. I watch Dutch channels more with English subtitles and I read Dutch books.' (Sare)

Annem çok izler, ben sevmem, kapatırım.

'My mom watches a lot, I don't like. I turn it off.' (Tolga)

When it came to the question about 'teaching their children Turkish in the future', one of them doubted it, three of them said that they would not, considering their Turkish is not good enough to teach. All of them pointed out that they would marry a Dutch person, and would never leave the Netherlands to move to Turkey.

As for their feelings, the first generation Turkish-Dutch bilinguals claimed that they feel more comfortable while speaking Turkish and prefer to speak Turkish when they talk about their emotions. Conversely, the second and third generation bilinguals emphasized that they feel uneasy when they speak only Turkish without switching into Dutch, particularly when they have to communicate with a native Turkish speaker. These findings might be a sign of the anxiety that appears among Turkish-Dutch bilinguals of the second and third generations, who assert that they do not speak Turkish as well as a native Turkish speaker. Six of them remarked that they do not know all the words in Turkish, and Turkish is more difficult than 
Dutch. Misra explained her feeling of anxiety as resulting from her lack of proficiency in Turkish:

Bazen orda kuzenimin arkadaşlarıla oynamak istiyorum, birşey söylemek istiyorum ama duruyorum. Çoğunda konuşamıyorum çünkü ordaki insanlar, Türkçe’yi iyi biliyor, ben bilmiyorum ve ne dediğimi anlamiyorlar, daha da kötü oluyor. Ben de Türkçe anlatamayınca annemi babamı arıyorum onlara Hollandaca diyorum. Ondan sonra onlar söylüyor.

'Sometimes, I want to play with my cousin's friends there (in Turkey), and I want to say something, but I stop. I can't talk most of the time, because the people there know Turkish very well, but I don't. And they mostly don't understand what I say. And it gets worse. When I can't explain it in Turkish, I call my mother or father and tell them in Dutch. Then, they are telling the people.

Mesut, from the second generation, touches on the topic of native Turkish people's attitudes and calls the communication in Turkey outside the family 'different' and 'insufficient'. This might also be one of the possible reasons for anxiety:

Türkiye'ye gittiğim zaman tatilde falan ordaki akrabalarımıza kendimi ifade edebiliyorum, ama bazen şey duygusu olabiliyor. Türkiye'deki yaşayanlar böyle Avrupa'dan gelenlere farkl bir gözle bakiyorlar. Yani bu kesinlikle oluyor herkese oluyor yaniç Bu yüzden ordaki işte diyelim çarşılda olsun diyelim mahallede olsun işte aradaki iletişim sosyal iletişim biraz daha farkh olabiliyor, yetersiz kalabiliyor.

'When I go to Turkey for a holiday or so, I am able to express myself to my relatives there, but sometimes the feeling may arise that Turkish people who live in Turkey see the people who come from Europe with different eyes and from different angles. This surely happens to everybody I mean. That's why, say in the center or in the neighborhood, communication between us, the social communication there, gets a bit different and insufficient.'

\subsection{Findings based on elicitation data}

Lexical and structural characteristics of the participants' language use have shown that Turkish as spoken in the Netherlands differs from Turkish as spoken in Turkey. The types of phenomena and their frequencies vary across the generations and will be discussed in the following sub-sections.

\subsubsection{Lexical characteristics of NL-Turkish}

As shown in Table 2, the use of overt Dutch words was the most prevalent lexical phenomenon across three generations. A total of 33 loan translations were identified in the speech of both second (5) and third generation (28) bilinguals. The use of Dutch words followed by the Turkish auxiliary yap- ('to do'), was only found in the third generation speech $(\mathrm{N}=11)$. 
Table 2. Lexical characteristics of NL-Turkish

\begin{tabular}{llccc}
\hline Generation & Participants & overt NL words & $\begin{array}{l}\text { Loan } \\
\text { translations }\end{array}$ & $\begin{array}{l}\text { NL word } \\
+ \text { yapmak }\end{array}$ \\
\hline 1 & Nejat & 1 & 0 & 0 \\
& Sulhiye & 2 & 0 & 0 \\
& Mine & 10 & 0 & 0 \\
& Gunay & 3 & 0 & 0 \\
& Demet & 5 & 0 & 0 \\
& Gulsum & 17 & 0 & 0 \\
& Yunus & 12 & 0 & 0 \\
& Nilay & 22 & 2 & 0 \\
& Ozlem & 7 & 1 & 0 \\
& Mesut & 0 & 2 & 0 \\
3 & Tolga & 77 & 4 & 3 \\
& Sare & 159 & 7 & 1 \\
& Misra & 5 & 10 & 1 \\
& Kerem & 31 & 7 & 6 \\
& & 351 & 33 & 11 \\
\hline \multirow{3}{*}{ Total } & & & &
\end{tabular}

In total, the participants used 351 Dutch words. A considerable proportion of these $(76 \%)$ were used by the third generation bilinguals, who have little use of Turkish in their daily life (see Table 1). As Figure 1 shows, $13 \%$ of the third generation data consisted of Dutch words. Note that Mesut, Ozlem and Misra used only a few Dutch words, since they made a specific effort not to switch to Dutch. This resulted in a relatively frequent use of wrong Turkish words and substitutions in their speech, e.g. they called the chair a table, the elephant a man, etc., and they used şey, bir şey, öbür şey ('the thing', 'a thing,' 'the other thing') very often.

To identify relevant phenomena, the least frequent Dutch words, observed in only one participant's speech, were classified as 'insertional-code switching' (Muysken, 2000), e.g. jongen ('guy'), beker ('plastic cup'), kus ('kiss'), lekker ('nice'), gezondheid ('bless you'), taart ('cake') etc. On the other hand, as shown in Table 3, pannekoek ('pancake'), blik ('can') and hek ('fence') were frequently used by different bilinguals across the three generations, and were therefore considered to be 'established loanwords':

It is instructive to look into what makes pannekoek ('pancake') so borrowable (Thomason \& Kaufman, 1988). Two assumptions can be made. First, the bilinguals might associate this word only with Dutch culture, since pancakes are not as common in Turkish cuisine as they are in Dutch cuisine. Secondly, it is likely 


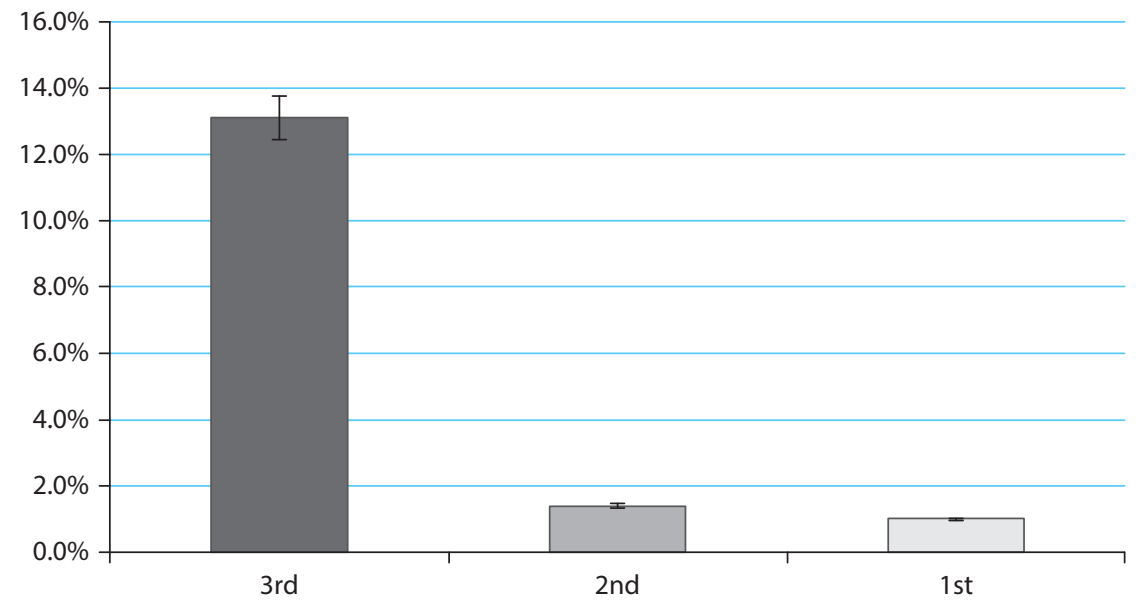

Figure 1. The use of Dutch overt words in Turkish across generations

Table 3. Cumulative percentages of the words pannekoek, blik and hek

\begin{tabular}{llcc}
\hline & pannekoek & blik & hek \\
\hline 1st generation & 42.9 & 21.4 & 7.1 \\
2nd generation & 57.1 & 28.6 & 14.3 \\
3rd generation & 85.7 & 50.0 & 42.9 \\
Total frequency & 12 & 7 & 6 \\
\hline
\end{tabular}

that the Dutch word is not equivalent to anything in Turkish. Even though krep ('crepe'), originally a French word, can be found on the menus of some restaurants in Turkey, it may not feel right for a Turkish-Dutch bilingual to refer to a pancake with the word for crepe.

Regarding the second phenomenon, 33 loan translations were found in the data. ${ }^{2}$ Among these, the highest frequencies were for el vermek ('to give hand'), used by 6 bilinguals, and Name of Instrument+oynamak ('to play'), used seven times by 5 different second and third generation bilinguals. That indicates these loan translations may be becoming fixed units in NL-Turkish. To see the Dutch interference in these combinations in more detail, their sources are presented below:

- TR-Turkish çalmak+instrument replaced by the unconventional use of oynamak+instrument in NL-Turkish: in both Dutch and English, the verb spelen ('to play') is used for both instruments and games. Turkish, on the other hand, has two different verbs for these situations. Oynamak is used for ('to play a game') while çalmak is used for instruments. In NL-Turkish, oynamak,

2. For the complete list of loan translations, see Sevinç $(2012,72)$ 
the literal translation of 'spelen', is used unconventionally as a result of Dutch influence:

(2) NL-Turkish: Fare gitar oyn-uyor. mouse guitar play-PROG3sG.

NL: $\quad$ 'De muis speelt gitaar.'

TR-Turkish: Fare gitar çal-ıyor. mouse guitar play-PROG3sG. 'The mouse is playing guitar'

- 'El sıkışmak' or 'tokalaşmak' ('to shake hands') replaced by 'el vermek' ('to give hands') in NL-Turkish: a word-by-word translation of the Dutch collocation een hand geven ('to give a hand') in Turkish has given rise to the loan translation 'el vermek'.

(3)

(3)

NL-Turkish: Herk everybody each other-DAT hand give-PROG3SG

NL: $\quad$ 'Iedereen geeft elkaar de hand'

TR-Turkish: Herkes birbiri-nin el-i-ni sı-ıyor. everybody eachother-GEN hand-POss3SG-ACC shake-PROG3SG 'Everybody is shaking each other's hand'

- The final phenomenon, Dutch words followed by the Turkish auxiliary yap('to do'), was observed only in third generation speech, with 11 examples. Table 4 gives the complete list.

Table 4. NL word+'yapmak' and the frequencies in third generation bilinguals' speech

\begin{tabular}{|c|c|c|c|}
\hline Tolga & Sare & Misra & Kerem \\
\hline $\begin{array}{l}\text { nies yapmak } \\
\text { ('to sneeze') }\end{array}$ & $\begin{array}{l}\text { trommelen yapmak } \\
\text { ('to drum') }\end{array}$ & $\begin{array}{l}\text { vastknopen yapmak } \\
\text { ('to tie') }\end{array}$ & $\begin{array}{l}\text { doormidden scheuren yapmak } \\
\text { ('to tear in half') }\end{array}$ \\
\hline \multirow[t]{4}{*}{$\begin{array}{l}\text { honkballen yapmak } x 2 \\
\text { ('to play baseball') }\end{array}$} & & & $\begin{array}{l}\text { dribbel } \\
\text { yapmak } x 2 \\
\text { ('to dribbel') }\end{array}$ \\
\hline & & & $\begin{array}{l}\text { lummelen yapmak } \\
\text { ('to loaf') }\end{array}$ \\
\hline & & & $\begin{array}{l}\text { aan elkaar naaien yapmak } \\
\text { ('to sew together') }\end{array}$ \\
\hline & & & $\begin{array}{l}\text { struikel yapmak } \\
\text { ('to stumble') }\end{array}$ \\
\hline 3 & 1 & 1 & 6 \\
\hline
\end{tabular}


These examples show that, contrary to the claim that all Dutch verbs are inserted in their infinitive forms when they are followed by an inflected form of yap- (Backus, 2009), bilinguals sometimes combine Dutch verb stems with yapmak. Apparently, the combinations of Dutch verb stems and Turkish infinitive yap- below are indications of the start of a change in NL-Turkish structure:

$$
\begin{array}{ll}
\text { dribbel+yapmak } & =\text { dribbelen ('to dribble'), } \\
\text { struikel+yapmak } & =\text { struikelen ('to stumble') } \\
\text { nies+yapmak } & =\text { niezen ('to sneeze') }
\end{array}
$$

In view of the fact that this phenomenon was observed to be frequent in second generation speech in previous research (Backus, 2009), one may wonder why we do not find it now in the second generation data. The reason for this might be that the total number of second generation participants tested is quite low. Nevertheless, it can also be concluded that even though second generation bilinguals may produce these constructions more often in their daily speech, they can keep them under control when they need to speak only Turkish.

\subsubsection{Structural characteristics of NL-Turkish}

The second phenomenon observed in NL-Turkish was the use of unconventional structures, either due to Turkish-Dutch language contact, lack of exposure to Turkish, or Dutch interference. In the speech data, 112 unconventional sentences were found in terms of the use of case markers, word order, postpositions, and the plural suffix.

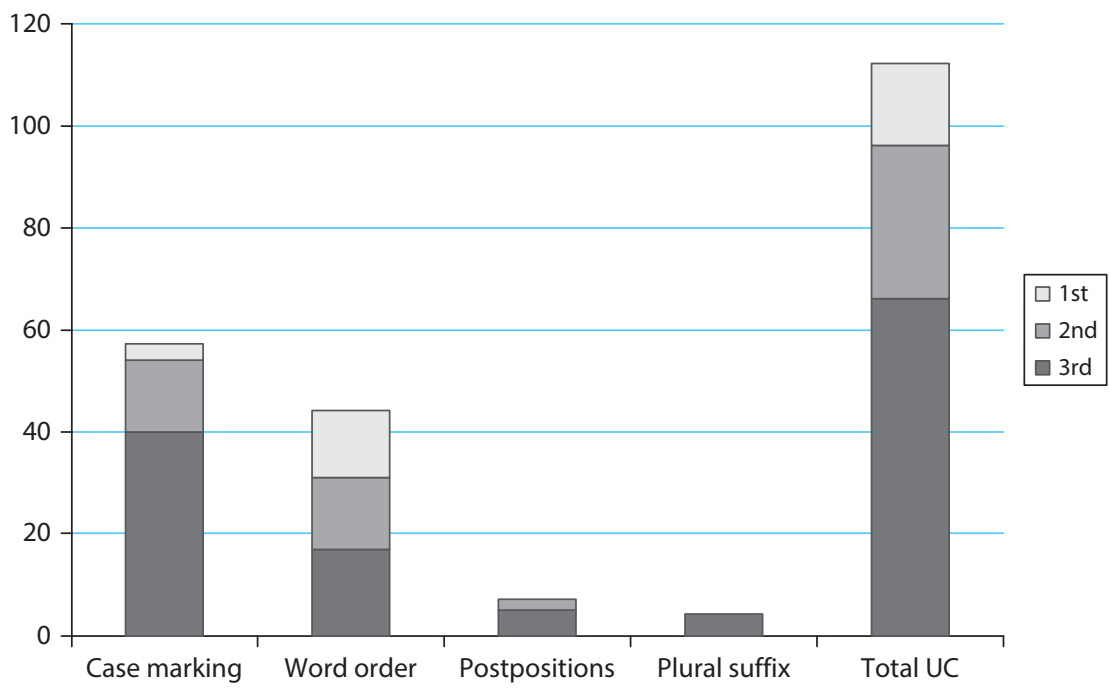

Figure 2. Number of unconventional Turkish structures observed in NL-Turkish across three generations 
Figure 2 illustrates that the large majority of the unconventional structures involved case marking, probably due to the typological distance between the case marking systems of the source (Turkish) and recipient (Dutch) language. Some of the unconventional utterances found in the data related to case marking are presented below:

(4) NL-Turkish: Kadın kişiler-e* selamlı-yor. the woman people-DAT greet-PROG3SG

TR-Turkish: Kadın kişiler-i selamlı-yor. the woman people-ACC greet-PROG3SG 'The woman is greeting people'

(5) NL-Turkish: Adam bir çocuğ- $\mathbf{u}^{*}$ kız-ıor. the man a boy-ACC get angry-PROG3SG

TR-Turkish: Adam bir çocuğ-a kız-ıyor. the man a boy-DAT get angry-PROG3sG 'The man is angry at a boy'

(6) NL-Turkish:Hek-in için-de* girmek isti-yor. fence-GEN in-LOC getINF want-PROG3SG

TR-Turkish: Hek-in için-e girmek isti-yor. fence-GEN in-DAT enterINF want-PROG3SG 'He wants to get into the fence'

(7) NL-Turkish: Adam arkasın-dan* saklanıyor. the man behind-ABL hide-Prog3sG

TR-Turkish: Adam arkasin-da saklanıyor. the man behind-LOC hide-PROG3sG 'The man is hiding behind him'

The most common case marking errors occur due to the confusion between the Turkish accusative and dative markers: in the NL-Turkish sentence (4), the expected accusative case marker is replaced by a dative case marker, whereas in (5) the accusative replaces the dative. In (6) the dative case marking is replaced by a locative case marker, and in (7) an ablative case marker replaces the locative.

As shown in Figure 2, the occurrence of word order unconventionality is also quite high and prevalent across generations. Since Turkish has SOV word order, as opposed to Dutch SVO order, adpositional phrases, in general, are placed in front of the verb by the third generation, as a result of Dutch interference:

(8) NL-Turkish:Fare bakıyor çöpün içine. the mouse look-PROG3sG dustbin-GEN in-DAT TR-Turkish: Fare çöpün içine bakıyor. the mouse dustbin-GEN in-DAT look-PROG3SG 
NL: $\quad$ De muis kijkt in de afvalemmer the mouse lookprog in the dustbin 'The mouse is looking inside the dustbin'

In addition, the results showed that the second and third generation bilinguals have difficulties with choosing the right postpositions in Turkish. Some of the errors occur because speakers confuse 'on' with 'in'.

(9) NL-Turkish: Kutu-yu sandalye-nin için-e* koy-du. box-ACC chair-GEN in-DAT put-PAST3sG

TR-Turkish: Kutu-yu sandalye-nin üzerin-e koy-du. box-ACC chair-GEN in-DAT put-PAST3sg 'He put the box on the chair'

Finally, the unconventional use of the Turkish plural suffix was observed only in the speech of third generation bilinguals. In Turkish, the suffix for indefinite plural is -ler or -lar. Unlike English or Dutch, Turkish does not require the plural suffix when a numeral is used with a noun. As a case of Dutch interference in their speech, bilinguals sometimes unconventionally attach a Turkish plural suffix to nouns following a numeral. Sentence (10) illustrates this:

(10) NL-Turkish: Iki adam-lar* yürü-yor.

two man-PL walk-PROG.3

TR-Turkish: Iki adam yürü-yor.

two man walk-PROG.3

NL: $\quad$ Twee man-nen wandelen.

two man-PL

'Two men are walking'

\section{Conclusions and discussion}

The aim of this paper was to report the findings of a small-scale study which investigated the issues of linguistic variation and change occurring in the NL-Turkish speech community in relation to the effects of social-emotional and linguistic aspects of contact.

A video elicitation experiment and interviews were conducted with bilinguals from three generations in a Turkish monolingual mode. The results from the elicitation experiment show that, due to its contact with Dutch and reduced exposure to Turkish, NL-Turkish has undergone considerable changes both in its lexicon and structure. Lexical changes are observed in all three generations, while the structural changes are only found in the younger generations. Most of 
the changes, particularly the cases of structural interference, the loan translations, and the combination NL word+TR yapmak appear to be used predominantly by the third generation, and are less frequent in the second generation.

Exploring the possible reasons for the conventionalization of some changes in the Turkish-Dutch bilingual community leads us to four linguistic factors. The first one is 'typological distance' (Field, 2002), referring to the differences between Dutch and Turkish structure. The fact that Dutch does not have equivalents might be the main reason for the changes in Turkish case marking, postpositions, and word order. The second factor is direct Dutch interference, which causes loan translations and the unconventional use of the Turkish plural suffix. The third reason might be the intensity of contact with Dutch (Thomason \& Kaufman, 1988) and the resulting lack of exposure to Turkish. This has probably reached its peak in the third generation and might be the reason why some changes regarding function words and structures only occur in the third generation. Finally, the attractiveness (Johanson, 2002) of the established loanwords suggests that the items connected to Dutch culture and the bilinguals' experiences, and those without a concrete Turkish equivalent, are more likely to be borrowed permanently in NLTurkish.

The interviews showed that there are differences across generations in social issues such as the values and feelings they have, their language preferences, and the amount of daily Turkish use. The data from the third generation, in which the emotional value and the daily use of Turkish are considerably lower, may predict a language shift in the Turkish immigrant community in the Netherlands. Being born and/or growing up in the Netherlands and interactions with Dutch friends or a Dutch partner have a major influence on this shift.

Turning to the relationship between the findings about social factors and the amount of unconventional Turkish use, this pilot study indicates that the first generation bilinguals who support maintenance the most, produced only small amounts of unconventional Turkish, including some Dutch words and two grammatical errors in case marking. On the other hand, the third generation bilinguals, who show the most adjustment to the Netherlands, used various unconventional utterances in Turkish, including extensive use of Dutch words, loan translations, NL words with TR auxiliary yap-, and several types of unconventional structure. Their higher proficiency in Dutch appears to lead to more intensive contact with Dutch language and culture, and this in turn causes lexical and structural changes in NL-Turkish.

Another important point is that there is also a link between 'language use and choice' across three generations, 'linguistic competence', and 'the heritage language anxiety' and 'negative self-image' that are the result of feeling unable to speak Turkish well. Based on the bilinguals' responses during the interviews, I 
hypothesize that this link forms a vicious circle, with more anxiety leading to less use of Turkish, which leads to reduced language knowledge, and this in turn leads to more anxiety.

Note, again, that all the results of this study must be interpreted with caution, since they are based on a limited number of participants, particularly in the younger generations. This pilot study suggests that it would be promising to carry out more research in various on-going contact situations, with more participants from different educational and social backgrounds. ${ }^{3}$ To obtain clearer results related to the reasons and the level of heritage language anxiety, future studies may consider combining the current methods with focus group discussions with bilinguals who experience heritage language anxiety. In addition, one could also construct an online translation task by asking bilinguals to say with which elements they associate the unconventional uses or loan translations. This could be a way to find out how conventionalized the new features are.

\section{Acknowledgements}

This study is the end result of my fortunate involvement in the Languages in Contact group, at the Department of Linguistics, Radboud University Nijmegen, in the Netherlands. I would like to express my graditude to Pieter Muysken, the chairman of Languages in Contact, for giving me the opportunity to participate in the ERC traces of contact project.

\section{References}

Backus, A. (1996). Two in one. Bilingual speech of Turkish immigrants in the Netherlands. Tilburg: Tilburg University Press.

Backus, A. (2009). Multidisciplinary approaches to code switching. In L. Isurin, D. Winford, \& K. de Bot (Eds.), Codeswitching as one piece of the puzzle of language change: The case of Turkish yapmak (pp. 307-336). Amsterdam: John Benjamins.

Backus, A., \& Dorleijn, M. (2009). Loan translations versus code-switching. In B.E. Bullock, \& A.J. Toribio (Eds.), The Cambridge handbook of linguistic code-switching (pp. 75-94). Cambridge: Cambridge University Press. DOI: 10.1017/CBO9780511576331.006

Backus, A. (2010). The role of codeswitching, loan translation and interference in the emergence of an immigrant variety of Turkish. Working Papers in Corpus-based Linguistics and Language Education, 5, 225-241.

3. Based on some of these results, the author is currently carrying out a $\mathrm{PhD}$ project, Language knowledge and linguistic anxiety across three generations of the Turkish immigrant community in the Netherlands: The effects of language shift, at the University of Oslo. 
Backus, A. (2013). Turkish as an immigrant language in Europe. In T.K. Bhatia, \& W.C. Ritchie (Eds.), The handbook of bilingualism and multilingualism (2nd ed.) (pp. 770-790). Oxford: Wiley Blackwell.

Croft, W. (2000). Explaining language change: An evolutionary approach. Harlow: Longman.

Dewaele, J.-M., Petrides, K.V., \& Furnham, A. (2008). Effects of trait emotional intelligence and sociobiographical variables on communicative anxiety and foreign language anxiety among multilinguals: A review and empirical investigation. Language and Learning, 58(4), 911-960. DOI: 10.1111/j.1467-9922.2008.00482.x

Doğruöz, A.S. (2007). Synchronic variation and diachronic change in Dutch Turkish: A corpus based analysis. Unpublished doctoral thesis. Tilburg University.

Doğruöz, A.S., \& Gries, S.Th. (2012). Spread of on-going changes in an immigrant language. Review of Cognitive Linguistics, 10(2), 401-426. DOI: 10.1075/rcl.10.2.07sez

Extra, G., \& Yağmur, K. (2010). Language proficiency and socio-cultural orientation of Turkish and Moroccan youngsters in the Netherlands. Language and Education, 24(2), 117-132. DOI: 10.1080/09500780903096561

Field, W.F. (2002). Linguistic borrowing in bilingual contexts. Amsterdam: John Benjamins. DOI: $10.1075 /$ slcs.62

Grosjean, F. (2012). An attempt to isolate, and then differentiate, transfer and interference. International Journal of Bilingualism, 16(1), 11-21. DOI: 10.1177/1367006911403210

Johanson, L. (2002). Structural factors in Turkic language contacts. London: Curzon.

Kerswill, P. (1994). Dialects converging: Rural speech in urban Norway. Oxford: Clarendon Press.

MacIntyre, P.D., \& Gardner, R.C. (1991). Investigating language class anxiety using the focused essay technique. Modern Language Journal, 75, 296-304. DOI: 10.1111/j.1540-4781.1991. tb05358.x

Muysken, P. (2000). Bilingual speech: A typology of code-mixing. Cambridge: Cambridge University Press.

Onar Valk, P., \& Backus, A. (2013). Syntactic change in an immigrant language: From non-finite to finite subordinate clauses in Turkish. Journal of Estonian and Finno-Ugric Languages, $4(2), 7-29$.

Phalet, K., \& Güngör, D. (2004). Religieuze dimensies, etnische relaties en burgerschap: Turken en Marokkanen in Rotterdam. In K. Phalet, \& J. ter Wal (Series Eds.), Moslim in Nederland, Deelstudie c (pp. 1-96). The Hague: SCP.

Sevinç, Y. (2012). Lexical and structural changes in Turkish spoken in the Netherlands. Linguistic and social factors in Turkish-Dutch contact. Master's thesis: Tilburg University.

Thomason, S., \& Kaufman, T. (1988). Language contact, creolization, and genetic linguistics. Berkeley: University of California Press.

Vedder, P., \& Virta, E. (2005). Language, ethnic identity and the adaptation of Turkish immigrant youth in the Netherlands and Sweden. International Journal of Intercultural Relations, 29(3), 317-337. DOI: 10.1016/j.ijintrel.2005.05.006

Yağmur, K. (2009). Language use and ethnolinguistic vitality of Turkish compared with the Dutch in the Netherlands. Journal of Multilingual and Multicultural Development, 30(3), 219-233. DOI: 10.1080/01434630802369445 